УДК 631:582.521.41:581.522.4(470.67) РЕЗУЛЬТАТЫ ПЕРВИЧНОЙ ИНТРОДУКЦИИ ПРЕДСТАВИТЕЛЕЙ РОДА
ИРГА (АMЕLANCHIER МЕDІК) В УСЛОВИЯХ ГОРНОГО ДАГЕСТАНА

Габибова А.Р., Залибеков М.Д.

ФГБУН ДФИЦ РАН «Горный ботанический сад», Махачкала, e-mail: aminat-gabibova@yandex.ru

\begin{abstract}
В представленной работе приведены результаты изучения нетрадиционных для Горного Дагестана представителей рода ирги Amelanchier Medik. Данные виды растений отмечены высокими показателями лечебных свойств и могут быть рекомендованы в профилактическом питании. Изучение особенностей биологии и выращивания растений этого рода в экстремальных условиях является весьма значимым. Исследования проводились на Гунибской экспериментальной базе Горного ботанического сада на высоте 1700 м над уровнем моря. Приводятся основные показатели по результатам изучения 5 видов ирги: ирга колосистая (A. spicata (Lam.) Koch.), ирга канадская (A. canadensis (Z.) Medik), ирга кроваво-красная (A. sanquinea (Purch)), ольхолистная (A. alnifolia) и ирга обильноцветущая (A. florida (Lindl.)) - в условиях Гунибского плато (1700 м над ур. м.) и Цудахара (1100 м над ур. м.) за период 1994-2018 гг. Показаны биологические и агротехнические характеристики выращивания растений видов рода Amelanchier Medik.: размножение, варианты посадки кустов, урожайность и рост. Изучаемые виды показали высокий уровень зимостойкости у изучаемых видов. В отдельные годы отмечены незначительные подмерзания побегов у ирги колосистой (до 10-15\%), которые не отразились на её росте и плодоношении. Оценка засухоустойчивости растений ирги показала, что все пять видов проявляли среднюю и высокую устойчивость к засухе. Возможность семенного размножения является существенным преимуществом ирги перед многими плодово-ягодными культурами, которых размножают в основном вегетативно. По морфологии куста, листьев, урожайности, по признакам плодов большинство растений ирги, выращенных из семян, показали низкую вариабельность. Установлено, что все интродуцированные виды имеют высокий адаптивный потенциал и хорошую возможность выращивания в условиях Горного Дагестана.
\end{abstract}

Ключевые слова: Amelanchier Medik, ирга, интродукция, горные условия, рост и урожайность, лечебные качества, размножение, Дагестан

\title{
RESULTS OF PRIMARY INTRODUCTION OF REPRESENTATIVES \\ OF THE GENUS SHADBERRY (AMELANCHIER MEDIK) IN THE CONDITIONS OF MOUNTAIN DAGESTAN
}

\author{
Gabibova A.R., Zalibekov M.D. \\ Mountain Botanical garden, Dagestan scientific center, Makhachkala, \\ e-mail: aminat-gabibova@yandex.ru
}

\begin{abstract}
The work is devoted to the study of non-traditional representatives of the irgi genus Amelanchier Medik. in Dagestan. These types of plants have very valuable therapeutic and preventive properties. The study of the biology and cultivation of plants of this genus in extreme climatic conditions of Mountain Dagestan is very relevant. The research was conducted at the Gunib experimental base of the Mountain Botanical garden at an altitude of $1700 \mathrm{~m}$. above the sea. The main results of the study of 5 species of shadberry are presented: A. spicata (Lam.) Koch., A. canadensis A. (Z.) Medic, A. sanquinea (Purch), A. alnifolia and A. florida (Lindl.) in the conditions of the Gunib plateau (1700 m above sea level. $\mathrm{m}$ ) and Tsudakhar (1100 m above sea level. M.) for the period 1994-2018. The biological and agrotechnical characteristics of Amelanchier Medik. cultivation are given: reproduction, planting and placement of bushes, growth and yield. The studied species showed a high level of winter hardiness in the studied species. In some years, there were slight freezing of shoots in A. spicata (up to 10-15\%), which did not affect its growth and fruiting. The assessment of the drought resistance of Amelanchier plants showed that all five species showed medium and high resistance to drought. The possibility of seed propagation is a significant advantage of Amelanchier over many fruit and berry crops, which are propagated mainly vegetatively. Most irgi plants grown from seeds are relatively similar in terms of Bush morphology, leaves, yield, size, shape, and color of fruits. It was found that all the tested species showed a high adaptive potential and a good possibility of growing in Mountain Dagestan.
\end{abstract}

Keywords: Amelanchier Medik, introduction, shadberry, mountain conditions, growth and yield, medicinal qualities, reproduction, Dagestan

Актуальной задачей ботанических садов является исследование новых перспективных видов растений, обладающих ценными хозяйственными признаками, и выявление приспособленных к условиям выращивания видов и сортов. Одними из таких растений являются представители рода ирга (Amelanchier Medik). Высокая устойчивость к зимним морозам, нетребо- вательность к почвенным и климатическим условиям, ежегодная высокая урожайность, хорошие вкусовые и лечебные качества плодов, устойчивость к биопатогенам - все эти показатели делают иргу одним из интересных растений для высокогорных районов с жестким климатом [1-3]. Работа посвящена памяти главного научного сотрудника, к.с.-х.н. Газиева Махача Абдулманаповича. 
В природе представители рода Amelanchier чаще всего встречаются в Cеверной Америке. В Европе достаточно обширное распространение уже с XVI века получили виды ирги A. spicata, A. grandiflora, A. lamarckii, A. confuse, A. alnifolia, A. canadensis $и$ A. arborea [1].

В природной флоре Кавказа род представлен только одним видом - A. rotundifolia (Lam.) Dum. - и. круглолистная. B естественных условиях этот вид произрастает на Кавказе (в Дагестане) и в Крыму, поднимаясь до 1900 м над ур. м. [3].

Растения ирги представлены крупными кустарниками или небольшими деревцами с простыми черешковыми тёмно-зелёными листьями с сизым оттенком, мелкими белыми цветками и чёрными плодами с синеватым отливом. Куст живет 50-60 лет, причем на смену усыхающим через 15-20 лет побегам вырастают новые.

Свое применение нашла ирга и в народной медицине для лечения болезней печени, почек, сердца, желудка и других заболеваний. Употребление плодов ирги действует успокаивающе на нервную систему, нормализуя сон, и укрепляет общее состояние организма. Ягоды используют для профилактики язвенной болезни и как противовоспалительное средство [4].

В культуре на Кавказе выращиваются четыре вида ирги: и. азиатская (A. asiatica (Sieb. et Zucc.) Endl.), и. канадская (A. canadensis (Z.) Medic), и. кроваво-красная (A. sanquinea (Purch)), и и. колосистая (A. spicata (Lam.) Koch.). Из всех видов ирги заслуживающими внимание являются ирга колосистая и канадская, как съедобные ягодные культуры [5; 6].

Впервые иргу для выращивания в России заметил сибирский плодовод И.П. Бедро [6], изучавший растение в Минусинске (Енисейская губерния) в начале XX века и рекомендовавший ее для широкого распространения в Сибири. Так, с 1950 г. иргу начали выращивать в промышленных садах Пермской области [7].

Цель работы - выявление биологических показателей представителей рода Amelanchier при интродукции в условиях Горного Дагестана и выделение наиболее ценных источников хозяйственных признаков для дальнейших селекционных исследований.

Для целедостижения были поставлены следующие задачи:

- выявить особенности фенологических наблюдений за интродуцированными вида- ми ирги и потенциал адаптации к горным условиям Дагестана;

- оценить продуктивность и урожайность интродуцированных видов ирги;

- выделить наиболее перспективные виды ирги для дальнейшей рекомендации выращивания в горных условиях Дагестана.

\section{Материалы и методы исследования}

В коллекции Горного ботанического сада проходят первичную интродукцию 5 видов: ирга колосистая (A. spicata), и. канадская (A. canadensis), и. кроваво-красная (A. sanquinea), и. ольхолистная (A. alnifolia) и и. обильноцветущзая (A. florida). Семена были получены по обменному фонду.

Впервые в условиях Дагестана с 20082018 гг. для изучения ирги проводили наблюдения на Гунибской экспериментальной базе (Гунибское плато) на высоте 1750 м над ур. моря. Два вида - и. колосистая (A. spicata) и и. обильноцветущзая (A. florida) - высажены на Цудахарской экспериментальной базе на высоте 1100 м над ур. моря.

Исследования проводились в соответствии с общепринятыми методическими руководствами [8; 9]. Изучались основные фазы вегетации с целью выявления отношения ирги к экологическим условиям изучаемого района - рост и урожайность, зимостойкость. Оценку и учет урожая проводили в среднем на куст весовым методом. При определении коэффициента вариации количественных признаков в качестве меры изменчивости использовалась эмпирическая шкала С.А. Мамаева [8].

\section{Результаты исследования и их обсуждение}

Результаты фенологических наблюдений показали, что в условиях экспериментальной базы на Гунибском плато растения ирги начинают вегетацию во второй декаде апреля, с колебаниями в отдельные годы с третьей декады марта (2008 г.) до первой декады апреля (2018 г.). Листопад завершается в основном во второй декаде октября, продолжительность вегетационного периода 190 дней. Листья средней величины острозубчатые, темно-зеленой окраски при распускании беловойлочные, летом темнозеленые, осенью - оранжево-красные.

Бутонизация совпадает с началом распускания листьев и приходится в основном на первую декаду мая. Цветки белые, цветение завершается во второй и третьей декаде мая, продолжительность 20 дней. Плодовая кисть до 5,6 см длины, среднее количество 
цветков в кисти 12,3 шт., ягод - 9,2 шт. Завязываемость ягод в кисти 75\%. Созревание плодов идет неравномерно в течение 20-30 дней, начинается с конца июня и продолжается до середины июля. Ягоды округлой формы, темно-пурпуровые. Средний размер плодов от 5/5 до 10/10 мм, масса ягоды 0,78 г, минимальная 0,74 г, максимальная 0,82 г, количество семян в ягоде $-6,5$ шт. (табл. 1).

Плодоносить начинают с третьего года посадки (24 г в среднем с 1 куста), стабильный урожай начинают давать с шестого года $(170$ г). Созревание плодов неодновременное на кисти у ирги, поэтому сбор урожая производят вручную в несколько приемов по мере созревания ягод. Вкус плодов пресно-сладкий. Свежие ягоды можно хранить 2-3 дня в комнатных условиях для употребления без вреда для качества.

И. колосистая - урожайное растение, она отзывчива на хороший уход, при подкормках и поливах хорошо растет и мо- жет дать в период полного плодоношения до 14 кг с куста [7]. Однако из-за неблагоприятных условий климата Гунибского плато максимальный урожай за годы исследований здесь составил до 1,5 кг (на 1113 годы посадки).

И. колосистая зимостойка (переносит морозы до $-40-50^{\circ} \mathrm{C}$, поднимаясь на высоту до 1900 м над ур. м.). Цветы достаточно устойчивы к весенним заморозкам, выдерживают понижение температуры до $-7^{\circ} \mathrm{C}[10]$. В условиях Гунибского плато повреждается морозами лишь в отдельные годы, среднее повреждение у нее за годы наблюдений составило $10 \%$.

Зима 2008/2009 гг. для ирги оказалась экстремальной из-за засушливого лета 2008 г. В этот год общее повреждение кроны кустов составило более 59\%, причем в основном были повреждены до $90 \%$ слабые кусты. Основные данные биометрических измерений роста и плодоношения приведены в табл. 2 .

Таблица 1

Фенология видов ирги на Гунибской экспериментальной базе

\begin{tabular}{|l|c|c|c|c|c|}
\hline \multicolumn{1}{|c|}{ Вид } & $\begin{array}{c}\text { Начало } \\
\text { вегетации }\end{array}$ & $\begin{array}{c}\text { Начало } \\
\text { цветения }\end{array}$ & $\begin{array}{c}\text { Конец } \\
\text { цветения }\end{array}$ & $\begin{array}{c}\text { Созревание } \\
\text { плодов }\end{array}$ & $\begin{array}{c}\text { Опадение } \\
\text { листьев }\end{array}$ \\
\hline Ирга колосистая & II дек. 04 & I дек. 05 & III дек. 05 & III дек. 06 & II дек. 10 \\
\hline Ирга канадская & III дек. 03 & II дек. 05 & I дек. 06 & II дек. 07 & II дек. 11 \\
\hline Ирга кроваво-красная & I дек. 04 & I дек. 05 & II дек. 06 & I дек. 07 & III дек. 10 \\
\hline Ирга ольхолистная & I дек. 04 & II дек. 05 & III дек. 06 & I дек. 07 & I дек. 11 \\
\hline Ирга обильноцветущая & II дек. 04 & I дек. 05 & II дек. 06 & I дек. 07 & III дек. 10 \\
\hline
\end{tabular}

Таблица 2

Показатели роста и плодоношения видов ирги в коллекциях на Гунибской и Цудахарской экспериментальной базах

\begin{tabular}{|c|c|c|c|c|c|c|c|c|c|}
\hline $\begin{array}{c}\text { Виды ирги, место } \\
\text { посадки, средние } \\
\text { данные за годы } \\
\text { наблюдений } \\
\text { и количество кустов }\end{array}$ & 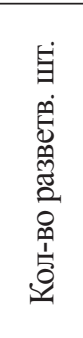 & 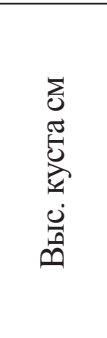 & 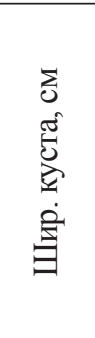 & 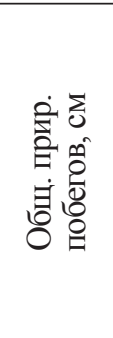 & 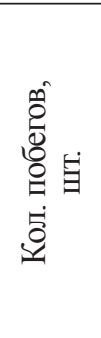 & 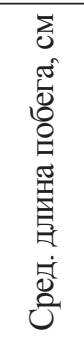 & 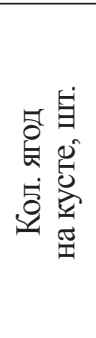 & 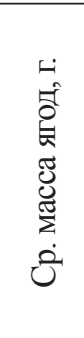 & 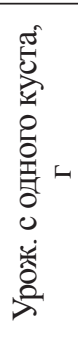 \\
\hline A. canadensis & 2,4 & 119 & 42 & 96 & 9,6 & 10,7 & 13 & 0,80 & 10,4 \\
\hline A. sanguine & 2 & 53 & 28 & 86 & 8,3 & 10,3 & 4,2 & 1,12 & 4,7 \\
\hline A. alnifolia & 1,7 & 47 & 22 & 79 & 9,5 & 8,5 & 6,5 & 1,00 & 6,5 \\
\hline A. spicata & 2,5 & 93 & 36 & 37 & 7,2 & 5,0 & 18 & 0,78 & 14,0 \\
\hline A. florida & 3 & 89 & 43 & 215 & 18,7 & 11 & 14 & 0,90 & 12,6 \\
\hline $\begin{array}{l}\text { Коэффициент вари- } \\
\text { ации CV\% }\end{array}$ & 24,9 & 33,8 & 28,5 & 73,8 & 48,2 & 30,8 & 60,2 & 15,3 & 40,1 \\
\hline $\mathrm{X} \pm \mathrm{Sx}$ & $\begin{array}{c}2,3 \pm \\
0,2\end{array}$ & $\begin{array}{c}70,5 \pm \\
11,9\end{array}$ & $\begin{array}{c}32,2 \pm \\
4,59\end{array}$ & $\begin{array}{c}104,2 \pm \\
38,47\end{array}$ & $\begin{array}{c}10,9 \pm \\
2,63\end{array}$ & $\begin{array}{l}8,7 \pm \\
1,34\end{array}$ & $\begin{array}{c}10,6 \pm \\
3,22\end{array}$ & $\begin{array}{c}0,9 \pm \\
0,07\end{array}$ & $\begin{array}{l}9,4 \pm \\
2,27\end{array}$ \\
\hline
\end{tabular}


Коэффициенты вариации габитуальных фенотипических ценопопуляций в посадках ирги колосистой в среднем за годы наблюдений в массе ягод $(24,56 \%)$ и длине плодовой кисти $(25,49 \%)$ характеризуются повышенным уровнем изменчивости. По всем остальным показателям был отмечен высокий и очень высокий уровень фенотипической изменчивости.

Растения $и$. анадской дают до 6 корнеотпрысков, рост побегов составил 20-25 см, молодые листья зеленые с розоватым цветом, осенью становятся темно-красными. Цветение продолжается 7-10 дней, цветки у этого вида крупные, расположены в рыхлых соцветиях до 25-28 мм. Средняя длина плодовой кисти 6,1 см, количество цветков в кисти 14,2 шт., ягод 12 шт. Полезная завязь составляет в среднем 84,5\%. Ягоды среднего размера, округлой формы, темнопурпуровой окраски с сизым налетом, кисло-сладкие, с мясистой темно-розовой мякотью, созревают в начале августа. Средняя масса ягоды данного вида - 1,04 г, максимальная - 1,10 г. Вкус ягод кисло-сладкий, с многочисленными семенами от 6 до 9 шт. в ягоде, с удельным весом 9,9\%.

И. кроваво-красная в посадке с 2012 г. По состоянию на октябрь 2018 г. высота кустов составила $65 \mathrm{~cm}$, ширина $40 \mathrm{~cm}$, общий годовой прирост на куст до 100 см, средняя длина побега 10 см. Вегетирует с середины апреля до начала октября. Листья среднего размера, темно-зеленые, с незначительным опушением, овально-продолговатой формы со средней длиной листа 5,5 см. Яркозеленая окраска листьев осенью меняется на оранжевую. Цветение начинается в середине мая продолжительностью до 10 дней. Цветки крупные, с удлиненными лепестками. Плодовая кисть от 5,7 до 6,6 см длины. Ягоды округлой формы со средней массой 1,12 г. и максимальной - 1,29 г. В ягоде в среднем от 5 до 8 шт. семян, их удельный вес составляет 9,5\%. Количество ягод на кусте составило 12 шт. Вкус ягод сладкий. Родина - северо-восток Северной Америки. Кустарник до 3 м высотой.

Ирга ольхолистная в посадке с 2012 г. По состоянию на октябрь 2018 г. высота куста составила 60 см, ширина 35 см, общий годовой прирост на куст до 100 см, средняя длина побега 10 см. Листья простые, острозубчатые, светло-зеленой окраски. Цветение продолжительное, от 3 до 4 недель, цветки белые. Длина плодовой кисти 5-6 см, в кисти в среднем от 4 до 10 плодов. Плоды округлой формы, синевато-черные, сочные и умеренно сладкие, в кисти до 12 плодов, крупные (средняя масса 1,0 г). Количество ягод на кусте составило 16 шт.

И. ольхолистная - это обычно небольшое деревце или кустарник высотой до 2-4 м, образующий густые заросли в западной и центральной частях Северной Америки. В культуре с 1918 г., устойчив к засухе и морозам, не болеет и не повреждается вредителями $[5 ; 10 ; 11]$.

На Цудахарской экспериментальной базе были посажены кусты ирги колосистой весной 2010 г. Из них только один куст дал три разветвления, остальные имели по одному стволу. Средний диаметр ствола составил 13 мм, высота кустов 104 см, ширина 47 см, общий прирост побегов 50 см. Урожай незначительный - до 10-35 ягод на кусте.

И. обильноиветущчая в 2010 г. была получена посевом семян, в 2012 г. они были пересажены. К 2018 г. средняя высота кустов составила 89 см, ширина 43 см, образовали в среднем по три разветвления на куст, общий прирост на куст составил 215 см, количество плодов - от 9 до 30 ягод на куст.

Листья округлые, острозубчатые в верхней половине, средней величины, зеленые. Листовая пластинка снизу опушенная. Цветёт в апреле-мае продолжительностью 1518 дней. Цветки белые с крупными лепестками, собраны в кисти - 13 шт., ягод - 10,6 шт. длина плодовой кисти 5,0 см, плоды округлые, тёмно-пурпурные, созревают в июле-августе. Завязываемость ягод $81,5 \%$. Средняя масса ягоды 0,90 г, максимальная 0,94 г, количество семян в ягоде - 9,9 шт., удельный вес семян в ягоде $-9,8 \%$. Вкус ягоды сладкий.

Отличается крупными цветками, обильным цветением и эффективными плодами. Размножается преимущественно корневой порослью и прививками.

Это куст до 4-5 м высотой. Вид не поражается болезнями и вредителями. Устойчив к засухе, выдерживает морозы $50{ }^{\circ} \mathrm{C}$. Урожай с куста около 5,6 кг.

Коэффициенты вариации габитуальных фенотипических ценопопуляций в посадках видов ирги в среднем за годы наблюдений в средней массе ягод $(15,26 \%)$, в количестве разветвлений $(24,87 \%)$, ширине куста $(28,46 \%)$ характеризовались повышенным уровнем изменчивости. По всем остальным показателям были отмечены высокий и очень высокий уровень фенотипической изменчивости.

Ирга размножается семенами, порослью, черенками и делением кустов. При размножении семенами желательно стра- 
тифицировать на протяжении трех месяцев при температуре $+1+5^{\circ} \mathrm{C}$.

Вегетативно иргу размножают корневыми отпрысками (порослью), делением куста, зеленым черенкованием и прививкой. В наших исследованиях наиболее эффективным оказалось размножение ирги колосистой корневыми отпрысками, т.к. ирга в процессе своего роста дает большое количество корневых отпрысков, образующихся вокруг куста в радиусе до 1,5 метров. Таких корневых отпрысков на один куст ежегодно образуется до 5-6 шт.

Таким образом, на примере экспериментальных работ по ирге, проведенных на базах Горного ботанического сада, расположенных на двух высотах (1100 и 1750 м над ур. м.), можно утверждать, что условия выращивания в горном и высокогорном Дагестане вполне благоприятны для выращивания $u$. колосиcтой (A. spicata), и. канадской (A. canadensis), и. кроваво-красной (A. sanquinea), и. ольхолистной (A. alnifolia) и и. обильноиветущей (A. florida), при условии размещения их на плодородных освещенных участках.

\section{Выводы}

1. Культура ирги является перспективной для рекомендации к выращиванию в условиях Горного Дагестана. Изучение видов ирги в условиях интродукции на двух высотах позволило выделить наиболее устойчивые и ценные виды по комплексу хозяйственно значимых характеристик: и.колосистой (A. spicata), и.канадской (A. canadensis ), и. кроваво-красной (A. sanquinea), и. ольхолистной (A. alnifolia) и и. обильноиветущей (A. florida).

2. Все виды, интродуцируемые в Горном ботаническом саду, за вегетационный период успевают пройти все основные фенологические фазы, что свидетельствует об их значительном адаптационном потенциале.

3. Исследование ирги в условиях Горного и Высокогорного Дагестана свидетельствует о высоком уровне зимостойкости у изучаемых видов. Незначительные подмерзания побегов (до 10-15\%), отмеченные у ирги колосистой в отдельные годы, никак не отразились на её росте и плодоношении. Все изученные виды показали среднюю и высокую степень засухоустойчивости.

4. Существенным преимуществом ирги оказалась возможность размножения семенами. Большинство растений ирги, выращенных из семян, по морфологии куста, листьев, урожайности, величине, форме и окраске плодов сравнительно одинаковы.

\section{Список литературы / References}

1. Корунчикова В.В. Особенности биологии, экологии и перспективы использования интродуцированных видов ирги // Бюллетень государственного Никитского ботанического сада. 2013. № 103. С. 25-32.

Korunchikova V.V. Peculiarities of biology, ecology and perspectives of using the introduced shadberry species// Bulleten Gosudarstvennogo Nikitskogo botanicheskogo sada. 2013. № 103. P. 25-32 (in Russian).

2. Степанова А.В., Сорокопудов В.Н., Сорокопудова О.А., Степанова Д.В., Мячикова Н.И. Качество плодов видов ирги в условиях Белгородской области // Современные проблемы науки и образования. 2014. № 1. [Электронный ресурc]. URL: http://www.science-education.ru/ru/article/ view?id=11222 (дата обращения: 04.02.2021).

Stepanova A.V., Sorokopudov V.N., Sorokopudova O.A., Stepanova D.V., Myachikova N.I. Quality of fruits of types of the mespilus in the conditions of the Belgorod region// Sovremennie problemi nauki i obrazovaniya. 2014. № 1. [Electronic resource]. URL: http://www.science-education.ru/ru/article/ view?id=11222 (date of access: 04.02.2021) (in Russian).

3. Цвелев Н.Н. О роде ирга (Amelanchier medik., Rosaсеае) в Европейской России // Новости систематики высших растений. 2010. Т. 42. С. 174-177.

Tzvelev N.N. On the genus Amelanchier Medik. (Rosaceae) in the European Russia // Novosti sistematiki visshikh rastenii. 2010. T. 42. P. 174-177 (in Russian)

4. Лаксаева Е.А. Факторы, влияющие на накопление в плодах ирги биологически активных веществ // XXI век: Итоги прошлого и проблемы настоящего плюс. 2011. № 1. С. 60-63.

Laksaeva E.A. Factors influencing accumulation of bioactive substances in berries of Amelanchier vulgaris // XXI vek: Itogi proshlogo i problemi nastoyashego plus. 2011. № 1. P. $60-$ 63 (in Russian).

5. Стрельцина С.А., Бурмистров Л.А. Биохимический состав плодов ирги ольхолистной (Amelanchier alnifolia Nutt.) в условиях северо-западного региона России // Нетрадиционные и редкие растения, природные соединения и перспективы их использования: VII Международный симпозиум (Белгород, 24-27 мая 2006 г.). Белгород. 2006. Т. 1. С. 319-323.

Strel'cina S.A., Burmistrov L.A. Biochemical composition of the fruits of the alderberry irga (Amelanchier alnifolia Nutt.) in the conditions of the north-western region of Russia // Netradicionnye i redkie rasteniya, prirodnye soedineniya i perspektivy ih ispol'zovaniya: VII Mezhdunarodnyj simpozium (Belgorod, 24 27 maya 2006 g.). Belgorod, 2006. Vol. 1. P. 319-323 (in Russian).

6. Степанова А.В. Эколого-биологическая оценка генофонда ирги (A. medik.) при интродукции в условиях юго-запада ЦЧО: автореф. дис. ... канд. биол. наук. Рамонь, 2015. 18 с.

Stepanova A.V. Ecological and biological assessment of the irgi genofond (A. medik.) when introduced in the south-west of the CCHR: avtoref. dis. ... kand. biol. nauk. Ramon', 2015. 18 p. (in Russian).

7. Брыксин Д.М., Хромов Н.В. Основы промышленного возделывания жимолости и ирги в условиях Тамбовской области // Вестник МичГАУ. 2012. № 3. С. 89-93.

Bryksin D.M., Khromov N.V. The principles of commercial honeysuckle and serviceberry production in Tambov region // Vestnik MichGAU. 2012. № 3. P. 89-93 (in Russian).

8. Программа и методика сортоизучения плодовых, ягодных и орехоплодных культур. Орел, 1999. 605 с.

Program and methodology of variety study of fruit, berry and nut crops. Orel, 1999. 605 p. (in Russian).

9. Зайцев Г.Н. Математика в экспериментальной ботанике. М.: «Наука», 1990. 296 с.

Zajcev G.N. Mathematics in Experimental Botany. M.: «Nauka», 1990. 296 p. (in Russian).

10. Хромов Н.В. Оптимизация технологии возделывания ирги в условиях ЦЧР // Агроэкологические аспекты устойчивого развития АПК: материалы XII международной научной конференции. 2015. С. 104-107.

Khromov N.V. Optimization of irgi cultivation technology in the conditions of the CDR // Agroecologicheskye aspecti ustoichivogo razvitiya APK: materiali XII megdunarodnoy nauchnoy konferencii. 2015. P. 104-107 (in Russian).

11. Степанова А.В., Сорокопудов В.Н., Сорокопудова О.А., Степанова Д.В. Продуктивность некоторых видов рода Amelanchier Medik // Вестник НГАУ. 2012. № 2 (23). С. 26.

Stepanova A.V., Sorokopudov V.N., Sorokopudova O.A., Stepanova D.V. Productivity of some Amelanchier Medik varieties in Belogorje// Vestnik NGAU. 2012. № 2 (23). P. 26 (in Russian). 